\title{
DISTANCE EDUCATION AND VOCABULARY PODCASTING TASKS: ATTITUDE IN FOCUS
}

\author{
Atefeh ELEKAEI \\ ORCID: 0000-0001-5640-3026 \\ English Department, Islamic Azad University, Isfahan (Khorasgan) Branch \\ Isfahan, Iran \\ Dr. Hossein Heidari TABRIZI \\ ORCID: 0000-0002-9360-1555 \\ English Department, Islamic Azad University, Isfahan (Khorasgan) Branch \\ Isfahan, Iran \\ Dr. Azizeh CHALAK \\ ORCID: 0000-0002-6701-8366 \\ English Department, Islamic Azad University, Isfahan (Khorasgan) Branch \\ Isfahan, Iran
}

Received: 27/06/2018 Accepted: 24/07/2018

\section{ABSTRACT}

Distance education is a development in teaching and learning. Learners work and learn on their own at a distance from teachers and instructors with a degree of independence. The most important problem confronted by EFL learners is that they do not have enough time to be present in classes and they want to be taught through distance language education. The present study is an investigation of the effect of Iranian EFL learners' attitude regarding their distance vocabulary gain and retention. 180 participants took part in the present study. Two separate one-way multivariate analysis of variance (one-way MANOVA) were run in order to answer the questions. Results revealed that attitude levels significantly affected Iranian EFL learners' vocabulary gain and retention. The participants who had higher attitude levels had higher levels of vocabulary gain as well as retention applying audio podcasts plus still pictures and audio podcasts plus animated pictures.

Keywords: Distance education, vocabulary podcasting tasks, vocabulary gain, vocabulary retention, attitude.

\section{INTRODUCTION}

Numerous forms of Internet-based communication tools are available with the advent of the internet and mobile technologies. New technologies give rise to academic developments and adopting them are required for suitable educational use. Instructors are becoming encouraged to prepare their learning resources and activities for flexible as well as collaborative environments. Moreover, educational resources such as articles, books as well as images can be digitized and distributed via the Internet. Podcasting is one of the technologies that has converted traditional audio broadcast into portable, digital media (Putman \& Kingsley, 2009). Podcasts motivate learners outside the classrooms and learners' positive attitude was indicated by several research (Ducate \& Lomicka, 2009; Lord, 2008; O’Bryan \& Hegelheimer, 2007). In addition, more attention is needed for further research in order to encourage learners to promote their lexical knowledge. Moreover, there has been a broad sense of interest in E-learning regarding the constraints of time and place. The growing availability of technology has led many researchers to improve technologies as means of 
improving learners' second language vocabulary skills. Application of Telegram would be exemplified as a technology for distance teaching of foreign vocabularies.

The nature of the problem confronted by EFL learners is that they do not have enough time to be present in classes and they were taught through distance language education. Therefore, Telegram was utilized as a technology for distance teaching of foreign vocabularies in the present study. This study also concentrated on tasks in order to support learners to make sophisticated choices regarding distance language learning. In addition, while some studies (Chan, Chi, Chin \& Lin, 2011; Ducate \& Lumika, 2009; Li, 2010; O’Bryan $\&$ Hegelheimer, 2007) have discovered the application of podcasting in language learning, there is still little research regarding learners' perceptions as well as attitudes. Therefore, this study examined the attitude of Iranian EFL learners towards using podcasts in learning vocabulary.

\section{LITERATURE REVIEW}

\section{Distance Education}

Efforts have been made to provide accurate definition of distance education or E-learning as it grows and becomes more complex. Moore (1993) proposes six processes that must be organized in each E-learning or distance education program. The processes include "presentation; support of the learner's motivation; stimulate analysis and criticism; give advice and counsel; arrange practice, application, testing and evaluation; and arrange for student creation of knowledge" (pp. 28-30). Ubon and Kimble (2004) believe that social presence is a requirement to create online learning communities. However, Picciano (2002) suggests that learners can cooperate without feeling the sense of belonging to the group although interaction may demonstrate presence. Technology facilitates collaboration as well as interaction. Distance education instructors can provide podcasts in order to support learning and teaching.

\section{Podcasts}

The word podcast is a combination of words 'iPod' and 'broadcast' (Istanto, 2011). However, Podcasts can be played not just by iPods but also by MP3 players and other types of media players on the computers and mobile devices. What makes podcasting special is the capacity they have for "subscription". It means that listeners can subscribe to their favorite podcasts through an RSS (Really Simple Syndication) feed. In addition, their computers as well as mobile phones will receive 'alerts" whenever new episodes have been posted. Moreover, when the program is opened, podcatcher software programs such as iTunes will download the new episodes automatically. There are two types of podcast: "radio podcasts" and "independent podcasts" (p. 117).

Podcasting signifies an innovative, exciting as well as different learning model in academic settings. Materials such as lectures, conference reports and research manuscripts can be recorded as audio and video files and transported to subscribing users. Evans (2008) believes that learners are more interested in learning in the form of podcasts than in the form of textbooks or traditionally conducted lectures since they are more familiar with technologies especially podcasts. However, podcasts have some disadvantages. Lee and Chan (2007) pointed out that "The shortcomings of audio appear to be in the area of providing complex and/or detailed information that needs to be heavily processed, logically deconstructed, committed to memory, or otherwise requires substantial concentration" (p. 90).

Putman and Kingsley (2009) consider podcasts opportunities which strengthen information from the classroom as well as remediate learners who require supplementary teaching or access to what has been discussed in the classroom. Sanjana (2014) examined the effect of podcasts in developing listening skills of students of the higher secondary level in Bangladeshi context. The findings showed that the students were interested in using podcasts in both classroom and outside of it in order to learn English better. Moreover, 
they enjoyed listening to podcasts in their mobile phones even in their leisure time that showed they were autonomous in learning English.

\section{Attitude}

One of the most important factors that significantly affect and facilitate language learning is attitude. Ajzen (2005) views attitude as "a disposition to respond favorably or unfavorably to an object, person, institution, or event" (p. 3). Moreover, Masgoret and Gardner (2003) believe that "attitude toward the learning situation refer to the individual's reaction to anything associated with the immediate context in which the language is taught" (p. 127).

Since it is difficult to motivate learners outside the classroom, podcasts can be used as tool in order to promote learners' motivation. As O'Bryan and Hegelheimer (2007) state, podcast can make intrinsic as well as extrinsic motivation among students.

Researchers have different ideas about learners' attitude towards using podcasts. Li (2010) believes that learners enjoy listening to podcasts and are interested in using them to improve their language skills. In addition, Chester, Buntime, Hammond and Atkinson (2011) remarked that although there are differences among the participants regarding using podcasts, the participants' attitude and satisfaction towards using podcasts are positive. However, the results of Lonn and Teasley's (2009) study indicated that students were less sure about whether podcasts could progress instructors' teaching although both instructors and students believe that podcasts helped students learn.

Attitude, effects as well as perceptions regarding podcasts have been investigated and positive attitude and effects were indicated by several research (Abdous, Camarena \& Facer, 2009; Ducate \& Lomicka, 2009; Lord, 2008). Lord (2008) examined the Spanish students' pronunciation abilities as well as attitudes regarding using podcasts. It was indicated that both pronunciation skills and attitudes of students were improved after participating in the podcasting projects.

Since Mobile Assisted Language Learning (MALL) technology becomes common in education, Abdous, Camarena, and Facer (2009) compared the academic benefits of integrating podcast into the curriculum contrary to using them as a supplemental/review tool. The results revealed that learners were more interested in using technology. In addition, they had academic benefits. Moreover, it has been reported that podcast technology can result in considerable benefits especially when it is used more than merely as a tool for reviewing.

Ducate and Lomicka (2009) investigated a study in order to find out whether podcasting can improve learners' pronunciation skills. Twenty-two students in intermediate German as well as French courses created five scripted pronunciation recordings and three spontaneous podcasts. The results indicated that podcast was perceived positively by learners and they enjoyed using podcasts throughout the semester.

Lonn and Teasley (2009) considered the perceptions, attitudes as well as use of podcasting reported by instructors and students at a large American Midwestern university. The findings showed that students used podcasts for reviewing concepts as well as issues explained in lectures. Moreover, students were less sure about whether podcasts could improve instructors' teaching although both instructors and students believe that podcasts helped students learn.

Li (2010) investigated the Hong Kong Students' perceptions towards using podcasts in learning English. The results showed that students enjoyed listening to podcasts and had interests in using them in order to improve their language skills. Chester, Buntime, Hammond and Atkinson (2011) considered the 
participants' attitude and satisfaction towards using podcasts. Based on the results, although there were differences among the participants regarding using podcasts, high levels of self-efficacy were reported.

Bolliger, Supanakorn, and Boggs (2010) examined the influence of podcasting on student motivation in an online environment. It was reported that students had moderate motivation using podcasts in online courses. Moreover, considerable differences were found in student motivation regarding class standing, prior online learning experiences as well as gender.

Contrary to Li (2010), Walls, Kucsera, Walker, Acee, McVaugh and Robinson (2010) examined students' readiness and attitudes towards repetitive and supplemental podcasting forms and found that students were not as much ready or eager as the authors thought they were to use podcasts for repetitive or supplemental learning purposes. However, they suggested that supplemental podcasts were valuable for students.

Chan et al. (2011) investigated the perceptions and attitude of 120 Chinese and 61 Korean language students towards using podcasts. It was reported that students had different and significant positive attitudes towards using podcasts. However, the podcasts' objectives and students' learning motivation, the mismatches between podcast design and students' expectations, requirements and preferences, the teacher inspiration and student preparation, and the experience and understanding of mobile learning were presented as reasons for having different attitudes.

Hasan and Hoon (2012) considered the ESL students' attitudes as well as perceptions in using podcasts. The findings showed that students were interested in using podcasts and their perceptions and attitudes were positive. Their improvements in language skills specially listening were reported.

Darwis (2016) considered the learners' perceptions towards using podcasts in learning English. The results showed that although the length of podcasts was too long, the learners had positive attitudes towards using podcasts. Moreover, they were more excited in learning English because the content as well as clear native pronunciation of the podcasts attracted their attentions.

Naseri and Motallebzadeh (2016) examined the impact of podcasts on Iranian upper-intermediate EFL learners' self-regulation ability as well as their perceptions toward using technology. The experimental group listened to podcast files and the control group listened to radio programs. Practices were done using cognitive as well as metacognitive strategies. The findings indicated learners' positive perceptions towards using podcasts in language learning. Moreover, the results showed that learners' self-regulation abilities were increased considerably.

\section{Vocabulary Knowledge}

Vocabulary knowledge is fundamental to learners' comprehension and production in the four skills. As Schmitt and Meara (1997) maintain, "there has been a growing realization that total language proficiency consists of much more than just grammatical competence" (p. 18). Hai-peng and Li-jing (2007) suggest that multimedia environment and vocabulary teaching are impressive techniques to develop learners' vocabulary as well as English level.

Having conducted a study, Plass, Chun, Mayer and Leutner (1998) found that learners remembered word translations much better when they received both visual and verbal annotations. Moreover, students realized the story better when they could choose their preferred mode of annotation. Al-Seghayer (2001) investigated the effect of image modalities (dynamic video and still picture) in improving vocabulary acquisition of 30 ESL students through a hypermedia-learning program. Printed text definition alone, printed text definition associated with still pictures, and printed text definition associated with video clips were the three situations which were examined. Based on the results, the video clips were more effective in teaching vocabularies. 
Mayer and Moreno (2002) considered whether computer-based multimedia learning including pictures (such as animation) and words (such as narration) fosters students understanding. The results revealed that words associated with narration and animation helped learners more than words alone. Moreover, words as narration and animation helped learners more than narration, animation and on-screen text. They concluded that providing animation and narration improves learners understanding more than animation, narration, and on-screen text.

$\mathrm{Lu}$ (2008) examined the effectiveness of SMS vocabulary lessons on mobile phones. The findings revealed that although technology limitations, unfamiliar presentations as well as learning activities prevented students from reading SMS lessons, students had positive attitudes regarding learning vocabulary in mobile phones.

Rimrott (2010) considered the usefulness of annotations for vocabulary learning. Learners received a translation, an example sentence and one of five annotation clusters including picture and gloss, definition and gloss, picture and audio presentation, definition and audio, and picture, audio, floss and definition. Two posttests were administered. The immediate vocabulary posttest showed that annotation clusters including a picture were considerably influential for both abstract and concrete words. However, the delayed posttest revealed that all annotation clusters were equally influential.

Shoar, Abidin and Pour-Mohammadi (2011) examined the impact of using podcasts as a revision tool in recalling English vocabulary items after teaching. Sixty-eight Iranian EFL learners were selected and they were divided into two groups. The first group learned vocabulary items in their textbooks by their teachers in classroom settings and the second group received the material as audio recordings on podcasts. The findings showed the positive impact of using podcasts in learning English vocabulary items as well as recalling them better.

Zarei and Elekaei (2012) conducted a study in order to investigate the impacts of motivation and attitude on learner autonomy and language learning strategies of Iranian EFL learners. The results revealed that there were significant relationships between motivation and learner autonomy and positive relationships between attitude and learner autonomy. Moreover, the level of motivation and attitude considerably affected students' choice of memory, compensation and affective strategies.

Elekaei, Faramarzi and Biria (2015) investigated 80 EFL learners' attitude toward audio-only, pictorial (stillimage) and video listening tests. Results showed that test-takers' attitude was negative towards audio-only listening test and video listening test. Test-takers mentioned that guessing the content of the passage was difficult in audio-only listening tests and they were distracted many times while they were taking the video listening tests. However, test-takers' attitude was positive towards pictorial listening test since they could predict the content.

Alshaikhi and Madini (2016) examined Saudi students' preparatory level and their teachers' perception about podcast in listening. 120 students and teachers participated in the study and an explanatory sequential design was used in order to collect data. The results showed that although the students had positive attitudes towards the use of podcasts, the teachers were more familiar with podcasts.

Shahid and Ali (2017) considered Saudi EFL learners' attitude towards the use of video podcasts in listening comprehension as well as the number of video podcasts they received. The participants were divided in to three groups. One of the groups received 5 video podcasts and the other groups received 10 and 15 video podcasts, respectively. The findings indicated that the learners' attitudes were positive towards using video 
podcasts in listening. Moreover, no considerable differences were found between the learners regarding the number of video podcasts.

The present study was an attempt to answer the following questions:

$>$ Does attitude significantly affect Iranian EFL learners' vocabulary gain applying audio podcasts plus still pictures and audio podcasts plus animated pictures in an E-learning context?

$>$ Does attitude significantly affect Iranian EFL learners' vocabulary retention applying audio podcasts plus still pictures and audio podcasts plus animated pictures in an E-learning context?

\section{METHODOLOGY}

\section{Design}

The present study was an attempt to consider an experimental design to investigate the long-term effects of the treatment as the main part of the work in an E-learning project. The procedures include quantitative analysis. Samples of the study were selected randomly for both control and experimental groups. As Mackey and Gass (2005) suggest, the treatment process was ten weeks which is reasonable. An Oxford Placement Test was administered in order to homogenize the learners. Participants who achieve more than one standard deviation away from (above or below) the mean were excluded from the subsequent analyses and 180 learners were selected as the intermediate level learners.

\section{Participants}

Participants were selected from Iranian EFL learners (both male and female) learning English at Qazvin University of Medical sciences and Andisheh Nou Foreign Language Institute in Qazvin, Iran. A nonrandom purposive sampling was considered for the present study since this study concentrated on two groups of learners in an intermediate-level vocabulary proficiency and tested their improvement through the treatment period. Firstly, 280 learners were invited to the take part in the present study and take the proficiency test. An Oxford Placement Test was administered in order to homogenize the learners. Learners who achieved more than one standard deviation away from (above or below) the mean were excluded from the subsequent analyses and 180 learners were selected as the intermediate level learners. The learners' age was from 17 to 30. Their first language was Persian and they studied English as a foreign language.

\section{Instruments}

In order to answer the research questions, the following instruments were used:

$>$ Podcasting Tasks

$>$ Telegram Application

$>$ A proficiency test

$>$ An attitude questionnaire

$>$ An immediate vocabulary posttest

$>$ A delayed vocabulary posttest

A series of 120 audio podcasts plus still pictures as well as audio podcasts plus animated pictures were presented to the participants. The vocabularies were selected from 504 Absolutely Essential Words that each EFL learner must learn. Twelve new words were presented to the participants during six days of the week and one test including multiple-choice tests and filling the blanks assignments were given to the participants on the seventh days of the weeks. The participants were asked to complete the exercises and send them back. The incorporation of these tests supported learners in an online environment and made the current study distinct from previous studies.

The network-based technology does offer advantages over the traditional classrooms in terms of ease and range of access to materials and interlocutors. However, the network-based technology is not without 
difficulty. For instance, the teacher who is the most reliable source of input and feedback and who can best make decisions is removed in many network-based teachings. The question is how network-based technology can be effective while compensating for the problems constituted by the absence of real interaction. The idea of web-based learning has been implemented since the advent of the Internet. Telegram is the world's fastest messaging application. It is free and secure. Moreover, Telegram has no limits on the size of the media and chats. It lets people access their messages from multiple devices. Furthermore, Telegram is an opportunity for people to improve communication and collaboration. It allows people to integrate distinct sources of information into comprehensible schemas, capture and recall items or events that they would otherwise forget, enhance conversations by providing a way to exchange and share relevant information, and promote performing experiments and solving problems in the everyday world. Therefore, Telegram was implemented in the present study since the e-instructor was present and supported the participants by designing tests.

In order to homogenize the participants, a general proficiency test (Oxford Placement Test) was administered at the outset of the study. Then, a language learning attitude questionnaire on a five-point scale from "strongly disagree to "strongly agree" was sent to all participants in the telegram channel in order to understand the test-takers' attitudes, perceptions and feelings towards the project by the use of a voting robot system. The questionnaire was constructed by the authors and the internal consistency of the questionnaire was $\alpha=0.80$. Moreover, all of the items had item-total correlations of greater than 0.3 meaning that the questionnaire items were reliably measuring the same construct. The questions were presented to the participants on the main page of the channel. The participants could respond to the questions easily by touching the tabs. The researcher designed this questionnaire and the internal consistency as well as item-total correlations were checked. Next, an immediate vocabulary posttest in the form of multiple-choice was administered two weeks after the treatment in order to measure the participants' vocabulary gain via an E-learning program. Furthermore, a delayed vocabulary posttest in the form of multiple-choice and equivalent to the immediate vocabulary posttest was given to the participants four weeks after the treatment to investigate the test-takers' vocabulary retention in an online environment.

\section{Data Collection Procedure}

The following procedures were followed to attain the purpose of the current study. First, a general proficiency test was administered in order to make sure that there were no significant differences among the participants in terms of their proficiency level. The participants' scores on the general proficiency test were summarized. Moreover, the mean and the standard deviation were computed. Those who attained more than one standard deviation above or below the mean were excluded from others in order to take part in the treatment. In the second stage, a language learning attitude was sent to all participants in the telegram channel via @vote robot systems. The test-takers answered the questions by touching the tabs. Third, an immediate and delayed vocabulary posttest in the form of multiple-choice were administered two and four weeks after the treatment, respectively, in order to measure the participants' vocabulary gain and retention in an E-learning project. Finally, the obtained date were summarized, evaluated and prepared for further statistical analysis.

\section{Data Analysis Procedure}

To answer the research questions number one and two that are the effects of attitude on Iranian EFL learners' vocabulary gain and retention applying audio podcasts plus still pictures and audio podcasts plus animated pictures, two separate one-way multivariate analysis of variance (one-way MANOVA) were run.

\section{RESULTS}

The first research question attempted to see whether attitude significantly affects Iranian EFL learners' vocabulary gain applying audio podcasts plus still pictures and audio podcasts plus animated pictures in an 
E-learning context. To this end, participants were divided into three equal groups of high, medium and low levels of attitude according to their scores on the attitude questionnaire. To examine the effect of attitude levels on vocabulary gain (audio podcasts plus still pictures and audio podcasts plus animated pictures), a one-way multivariate analysis of variance was run. Preliminary assumption testing was conducted to check for normality, linearity, univariate and multivariate outliers, homogeneity of variance-covariance matrices, and multicollinearity, with no violations noted.

Table 1 illustrates the results of the descriptive and test statistics. Based on table 1, the participants who had high attitude level had the highest mean of vocabulary gain applying audio podcasts plus still pictures (mean $=93.83)$, followed by the participants who had medium attitude level (mean $=70.95)$, and the participants who had low attitude level (mean $=56.50)$. Moreover, the participants who had high attitude level had the highest mean of vocabulary gain applying audio podcasts plus animated pictures (mean $=110.87$ ), followed by the participants who had medium attitude level (mean $=97.92)$, and the participants who had low attitude level $($ mean $=85.70)$.

Table 1. Descriptive and test statistics for attitude levels and vocabulary gain (audio podcasts plus still pictures and audio podcasts plus animated pictures)

\begin{tabular}{ccccc}
\hline & Attitude Level & Mean & Std. Deviation & $\mathrm{N}$ \\
\hline Vocabulary Gain (Audio Podcasts & High & 93.83 & 5.205 & 60 \\
Plus Still Pictures) & Mid & 70.95 & 2.988 & 60 \\
& Low & 56.50 & 5.485 & 60 \\
& Total & 73.76 & 16.105 & 180 \\
\hline Vocabulary Gain (Audio Podcasts & High & 110.87 & 3.143 & 60 \\
Plus Animated Pictures) & Mid & 97.92 & 3.963 & 60 \\
& Low & 85.70 & 3.480 & 60 \\
& Total & 98.16 & 10.891 & 180 \\
\hline
\end{tabular}

Table 2 shows that attitude level significantly affected Iranian EFL learners' vocabulary gain applying audio podcasts plus still pictures and audio podcasts plus animated pictures in an E-learning context, $F(4,352)=$ $.000, p<.0005$, Wilks' Lambda $=.05$, partial eta squared $=.76$.

Table 2. Multivariate tests for attitude and vocabulary gain applying audio podcasts plus still pictures and audio podcasts plus animated pictures

\begin{tabular}{cccccccc}
\hline Effect & Value & F & $\begin{array}{c}\text { Hypothesis } \\
\text { df }\end{array}$ & $\begin{array}{c}\text { Error } \\
\text { Df }\end{array}$ & $p$ & $\begin{array}{c}\text { Partial } \\
\text { Eta } \\
\text { Squared }\end{array}$ \\
\hline Attitude Level & Wilks' Lambda & .057 & $281.868^{\mathrm{a}}$ & 4.000 & 352.000 & .000 & .762 \\
\hline
\end{tabular}

a. Exact statistic

Table 3 shows how dependent variables differ from the independent variables.

Table 3. Tests of between-subjects effects for attitude and vocabulary gain applying audio podcasts plus still pictures and audio podcasts plus animated pictures

\begin{tabular}{cccccccc}
\hline \multirow{2}{*}{ Source } & Dependent Variable & $\begin{array}{c}\text { Type III } \\
\text { Sum of } \\
\text { Squares }\end{array}$ & df & $\begin{array}{c}\text { Mean } \\
\text { Square }\end{array}$ & F & p & $\begin{array}{c}\text { Partial } \\
\text { Sta }\end{array}$ \\
& Squared \\
\hline \multirow{2}{*}{ Attitude Level } & $\begin{array}{c}\text { Vocabulary Gain (Audio Podcasts } \\
\text { Plus Still Pictures) }\end{array}$ & 42524.544 & 2 & 21262.272 & 964.935 & .000 & .916 \\
& $\begin{array}{c}\text { Vocabulary Gain (Audio Podcasts } \\
\text { Plus Animated Pictures) }\end{array}$ & 19006.211 & 2 & 9503.106 & 756.278 & .000 & .895 \\
\hline
\end{tabular}


Table 3 shows that attitude level significantly affected Iranian EFL learners' vocabulary gain applying audio podcasts plus still pictures $(F(2,177)=964.93 ; p<.0005$; partial eta squared $=.91)$ in an E-learning context. Table 4 includes Tukey's HSD post-hoc tests. Based on table 4, mean scores of vocabulary gain applying audio pictures plus still pictures there were statistically significant differences between high attitude level and medium attitude level $(p<.0005)$, high attitude level and low attitude level $(p<.0005)$, and medium attitude level and low attitude level $(p<.0005)$. Moreover, mean scores of vocabulary gain applying audio podcasts plus animated pictures show that there were statistically significant differences between high attitude level and medium attitude level $(p<.0005)$, high attitude level and low attitude level $(p<.0005)$, and medium attitude level and low attitude level $(p<.0005)$.

Table 4. Post hoc multiple comparisons of attitude levels and vocabulary gain applying audio podcasts plus still pictures and audio podcasts plus animated pictures

\begin{tabular}{ccccccccc}
\hline & & & & & & \multicolumn{2}{c}{$\begin{array}{c}\text { Confidence } \\
\text { Interval }\end{array}$} \\
\cline { 5 - 8 } Dependent Variable & $\begin{array}{c}\text { (I) } \\
\text { Attitude } \\
\text { Level }\end{array}$ & $\begin{array}{c}\text { Attitude } \\
\text { Level }\end{array}$ & $\begin{array}{c}\text { Mean } \\
\text { Differe } \\
\text { nce (I-J) }\end{array}$ & $\begin{array}{c}\text { Std. } \\
\text { Error }\end{array}$ & $P$ & $\begin{array}{c}\text { Lower } \\
\text { Bound }\end{array}$ & $\begin{array}{c}\text { Upper } \\
\text { Bound }\end{array}$ \\
\hline Vocabulary Gain (Audio & High & Mid & $22.88^{*}$ & .857 & .000 & 20.86 & 24.91 \\
Podcasts Plus Still & High & Low & $37.33^{*}$ & .857 & .000 & 35.31 & 39.36 \\
Pictures) & Mid & Low & $14.45^{*}$ & .857 & .000 & 12.42 & 16.48 \\
\hline Vocabulary Gain (Audio & High & Mid & $12.95^{*}$ & .647 & .000 & 11.42 & 14.48 \\
Podcasts Plus Animated & High & Low & $25.17^{*}$ & .647 & .000 & 23.64 & 26.70 \\
Pictures) & Mid & Low & $12.22^{*}$ & .647 & .000 & 10.69 & 13.75 \\
\hline
\end{tabular}

*. The mean difference is significant at the .05 level.

Figures 1 and 2 illustrates the differences between attitude levels and vocabulary gain applying audio podcasts plus still pictures as well as attitude levels and vocabulary gain applying audio podcasts plus animated pictures, respectively.

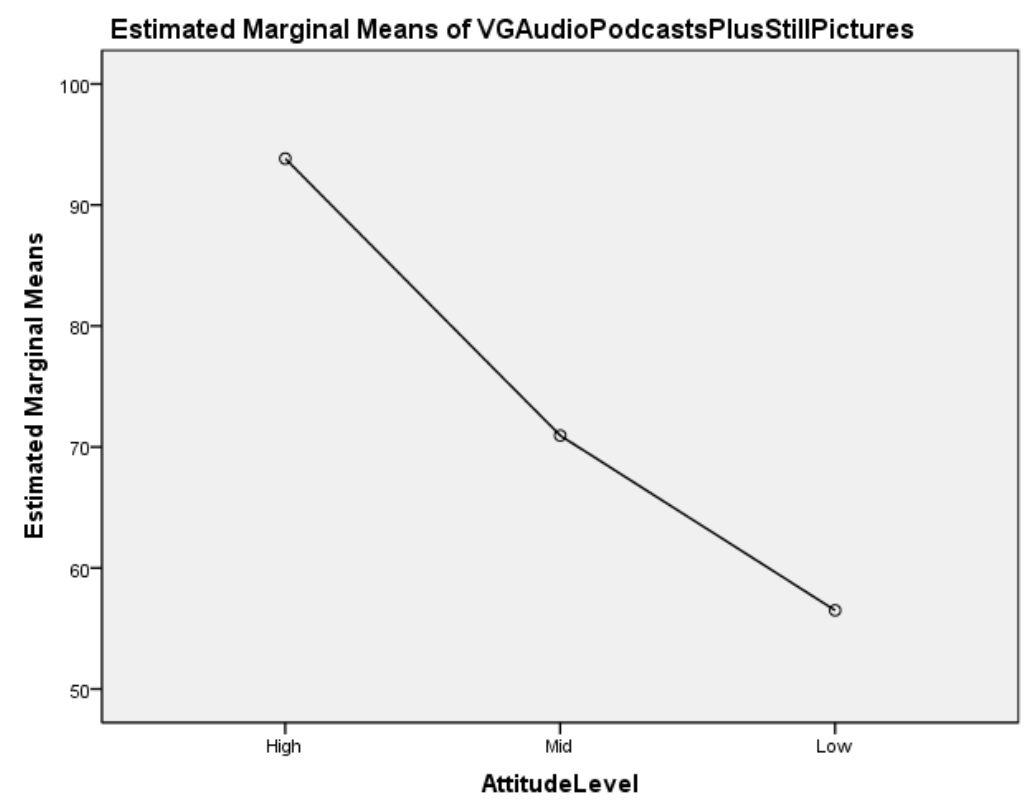

Figure 1. Attitude level and vocabulary gain applying audio podcasts plus still pictures 


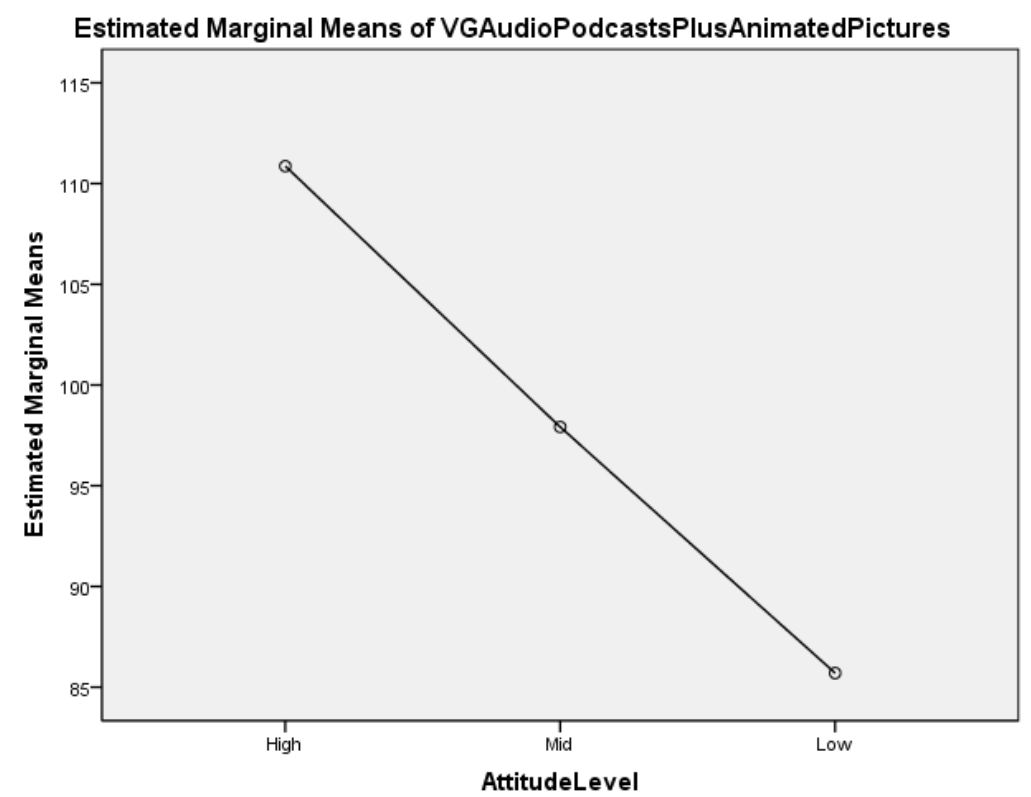

Figure 2. Attitude level and vocabulary gain applying audio podcasts plus animated pictures

The second research question attempted to see whether attitude significantly affects Iranian EFL learners' vocabulary retention applying audio podcasts plus still pictures and audio podcasts plus animated pictures in an E-learning context. To this end, participants were divided into three equal groups of high, medium and low levels of attitude according to their scores on the attitude questionnaire. To examine the effect of attitude levels on vocabulary retention (audio podcasts plus still pictures and audio podcasts plus animated pictures), a one-way multivariate analysis of variance was run. Preliminary assumption testing was conducted to check for normality, linearity, univariate and multivariate outliers, homogeneity of variance-covariance matrices, and multicollinearity, with no violations noted.

Table 5 shows the results of the descriptive and test statistics. Based on table 5, the participants who had high attitude level had the highest mean of vocabulary retention applying audio podcasts plus still pictures $($ mean $=100.57)$, followed by the participants who had medium attitude level $($ mean $=86.58)$, and the participants who had low attitude level (mean $=78.12$ ). Moreover, the participants who had high attitude level had the highest mean of vocabulary retention applying audio podcasts plus animated pictures (mean = 84.67), followed by the participants who had medium attitude level (mean $=65.98$ ), and the participants who had low attitude level $($ mean $=46.22)$.

Table 5. Descriptive and test statistics for attitude levels and vocabulary retention (audio podcasts plus still pictures and audio podcasts plus animated pictures)

\begin{tabular}{ccccc}
\hline & Attitude Level & Mean & Std. Deviation & $\mathrm{N}$ \\
\hline Vocabulary Retention (Audio & High & 100.57 & 3.412 & 60 \\
Podcasts Plus Animated Pictures) & Mid & 86.58 & 3.280 & 60 \\
& Low & 78.12 & 4.958 & 60 \\
& Total & 88.42 & 10.082 & 180 \\
\hline Vocabulary Retention (Audio & High & 84.67 & 4.024 & 60 \\
Podcasts Plus Still Pictures) & Mid & 65.98 & 6.601 & 60 \\
& Low & 46.22 & 3.928 & 60 \\
& Total & 65.62 & 16.511 & 180 \\
\hline
\end{tabular}


Table 6 shows that attitude level significantly affected Iranian EFL learners' vocabulary retention applying audio podcasts plus still pictures and audio podcasts plus animated pictures in an E-learning context, $F$ (4, $352)=.000, p<.0005$, Wilks' Lambda $=.07$, partial eta squared $=.73$.

Table 6. Multivariate tests for attitude and vocabulary gain applying audio podcasts plus still pictures and audio podcasts plus animated pictures

\begin{tabular}{|c|c|c|c|c|c|c|c|}
\hline & Effect & Value & $\mathrm{F}$ & $\begin{array}{c}\text { Hypothesis } \\
\text { df }\end{array}$ & $\begin{array}{c}\text { Error } \\
\text { Df }\end{array}$ & $\mathrm{p}$ & $\begin{array}{l}\text { Partial } \\
\text { Eta } \\
\text { Squared }\end{array}$ \\
\hline Attitude Level & Wilks' Lambda & .070 & $243.770^{a}$ & 4.000 & 352.000 & .000 & .735 \\
\hline
\end{tabular}

a. Exact statistic

Table 7 shows how dependent variables differ from independent variables.

Table 7. Tests of between-subjects effects for attitude and vocabulary retention applying audio podcasts plus still pictures and audio podcasts plus animated pictures

\begin{tabular}{clcccccc}
\hline \multirow{2}{*}{ Source } & \multicolumn{1}{c}{ Dependent Variable } & $\begin{array}{c}\text { Type III Sum } \\
\text { of Squares }\end{array}$ & df & $\begin{array}{c}\text { Mean } \\
\text { Square }\end{array}$ & F & p & $\begin{array}{c}\text { Partial Eta } \\
\text { Squared }\end{array}$ \\
\hline \multirow{3}{*}{ Attitude Level } & $\begin{array}{l}\text { Vocabulary Retention (Audio Podcasts } \\
\text { Plus Animated Pictures) }\end{array}$ & 15424.411 & 2 & 7712.206 & 492.535 & .000 & .848 \\
& $\begin{array}{l}\text { Vocabulary Retention (Audio Podcasts } \\
\text { Plus Still Pictures) }\end{array}$ & 44363.811 & 2 & 22181.906 & 884.976 & .000 & .909 \\
\hline
\end{tabular}

Table 7 shows that attitude level significantly affected Iranian EFL learners' vocabulary retention applying audio podcasts plus still pictures $(F(2,177)=492.53 ; p<.0005$; partial eta squared $=.84)$ in an E-learning context.

Table 8 includes Tukey's HSD post-hoc tests. Based on table 8 , mean scores of vocabulary retention applying audio pictures plus still pictures there were statistically significant differences between high attitude level and medium attitude level $(p<.0005)$, high attitude level and low attitude level $(p<.0005)$, and medium attitude level and low attitude level $(p<.0005)$. Moreover, mean scores of vocabulary retention applying audio podcasts plus animated pictures show that there were statistically significant differences between high attitude level and medium attitude level $(p<.0005)$, high attitude level and low attitude level $(p<.0005)$, and medium attitude level and low attitude level $(p<.0005)$.

Table 8. Post Hoc Multiple Comparisons of Attitude Levels and Vocabulary Gain Applying Audio Podcasts Plus Still Pictures and Audio Podcasts Plus Animated Pictures

\begin{tabular}{|c|c|c|c|c|c|c|c|}
\hline \multirow[b]{2}{*}{ Dependent Variable } & \multirow{2}{*}{$\begin{array}{c}\text { (I) } \\
\text { Attitude } \\
\text { Level }\end{array}$} & \multirow{2}{*}{$\begin{array}{c}\text { (J) } \\
\text { Attitud } \\
\text { e Level }\end{array}$} & \multirow{2}{*}{$\begin{array}{c}\text { Mean } \\
\text { Difference } \\
(\mathrm{I}-\mathrm{J})\end{array}$} & \multirow{2}{*}{$\begin{array}{c}\text { Std. } \\
\text { Erro } \\
\mathrm{r}\end{array}$} & \multirow[b]{2}{*}{$P$} & \multicolumn{2}{|c|}{$\begin{array}{l}\text { 95\% Confidence } \\
\text { Interval }\end{array}$} \\
\hline & & & & & & $\begin{array}{l}\text { Lower } \\
\text { Bound }\end{array}$ & $\begin{array}{l}\text { Upper } \\
\text { Bound }\end{array}$ \\
\hline Vocabulary Retention & High & Mid & $13.98^{*}$ & .722 & .000 & 12.28 & 15.69 \\
\hline (Audio Podcasts Plus & High & Low & $22.45^{*}$ & .722 & .000 & 20.74 & 24.16 \\
\hline Animated Pictures) & Mid & Low & $8.47^{*}$ & .722 & .000 & 6.76 & 10.17 \\
\hline Vocabulary Retention & High & Mid & $18.68^{*}$ & .914 & .000 & 16.52 & 20.84 \\
\hline (Audio Podcasts Plus Still & High & Low & $38.45^{*}$ & .914 & .000 & 36.29 & 40.61 \\
\hline Pictures) & Mid & Low & $19.77^{*}$ & .914 & .000 & 17.61 & 21.93 \\
\hline
\end{tabular}

*. The mean difference is significant at the .05 level. 
Figures 3 and 4 illustrates the differences between attitude levels and vocabulary gain applying audio podcasts plus still pictures as well as attitude levels and vocabulary gain applying audio podcasts plus animated pictures, respectively.

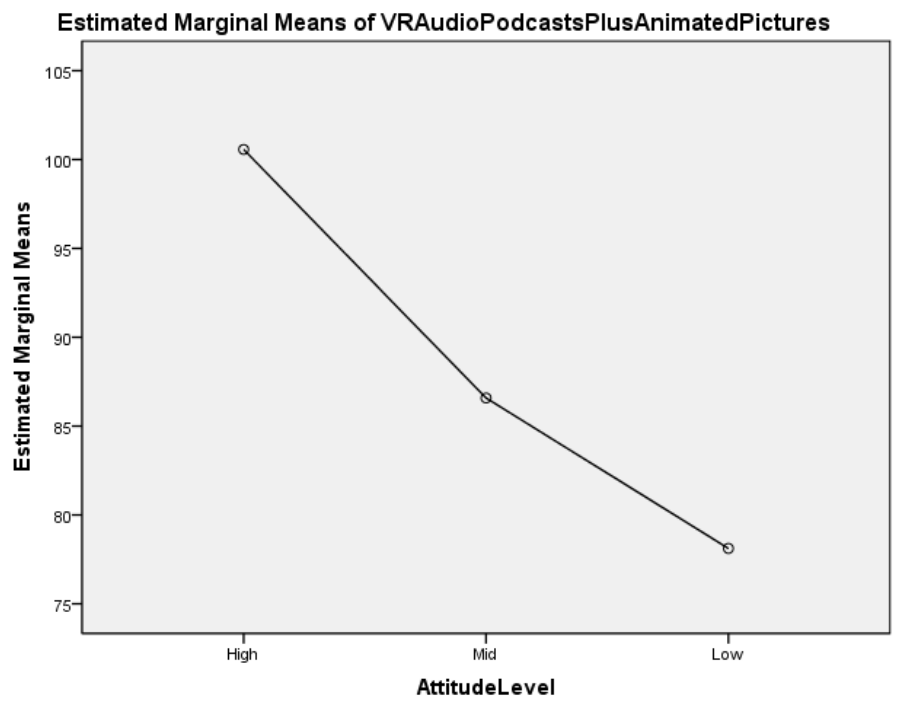

Figure 3. Attitude level and vocabulary gain applying audio podcasts plus still pictures

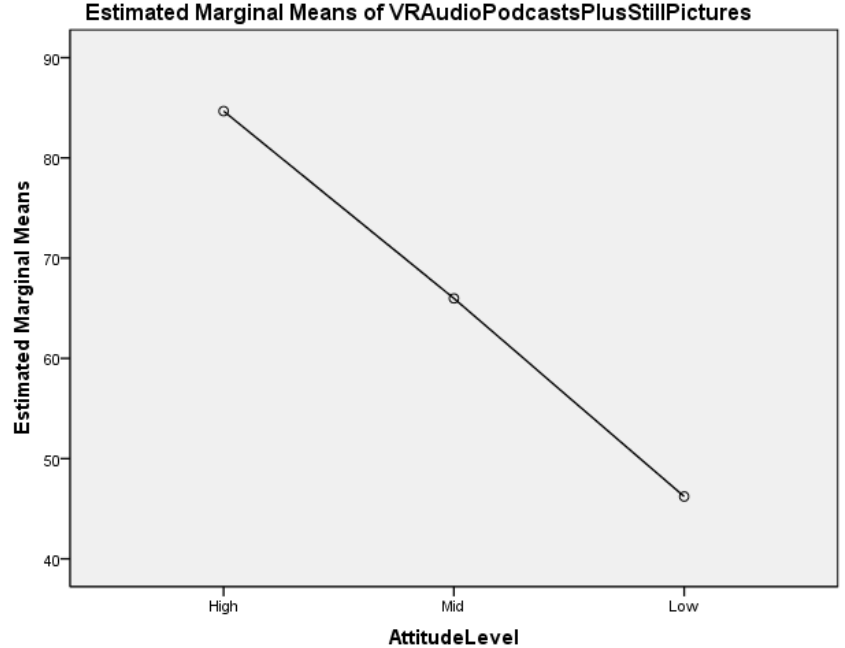

Figure 4. Attitude level and vocabulary gain applying audio podcasts plus animated pictures

\section{DISCUSSION}

The present study attempted to investigate the effects of learners' attitude on Iranian EFL learners' distance vocabulary gain and retention in an E-learning context. The findings of the present study was that attitude level significantly affected Iranian EFL learners' vocabulary gain as well as retention. The participants who had higher levels of attitude had higher levels of vocabulary gain as well as retention applying audio podcasts plus still pictures and audio podcasts plus animated pictures. These findings are in line with a number of other studies (Darwis, 2016; Evans, 2008; Lord, 2008; Sanjana, 2014). The present study is compatible with the study of Lee and Chan (2007) and Evans (2008), who found that students' anxiety reduced, their sense of inclusivity increased and students were more interested in learning in the form of podcasts. In addition, this finding is in line with the findings of Fernandez, Simo and Sallan (2009), who found that 
podcasts increased students' motivation by improving the contact between teachers and students. Moreover, the findings of the present study also corroborate those of Li (2010) and Sanjana (2014) who pointed out that the students enjoyed listening to podcasts and were interested in using podcasts in both classroom and outside of it in order to develop their language skills.

Furthermore, these findings are in accordance with those of Lord (2008), who reported that students' attitudes increased after participating in the podcasting projects. These results are also in line with the results of Abdous, Camarena, and Facer (2009), Ducate and Lomicka (2009), Chan et al. (2011), Hasan and Hoon (2012), Darwis (2016) and Naseri and Motallebzadeh (2016), who found that learners' attitude towards using podcasts was significantly positive, they became more excited in learning English and they were interested in using this technology. The findings of this study lead support to those of $\mathrm{Lu}$ (2008), who reported that students had positive attitudes regarding learning vocabulary in mobile phones and those of Shoar, Abidin and Pour-Mohammadi (2011), who showed that using podcasts had positive impacts on students' learning English vocabulary items and helped the students recall the items better. The results of this study also corroborate those of Elekaei, Faramarzi and Biria (2015), who found that test-takers' attitude was positive towards pictorial listening test.

This study also supports Alshaikhi and Madini's (2016) findings who showed that the students had positive attitudes towards the use of podcasts. The results of this study are in line with those of Shahid and Ali (2017), who reported that the learners' attitudes were positive towards using video podcasts in listening. However, the findings of the present study contradict those of Lonn and Teasley (2009). They found that although both instructors and students believed that podcasts helped students learn, students were less sure about whether podcasts could develop instructors' teaching. In addition, the results of this study are in contrast to those of Walls et al. (2010), who remarked that students were not as much eager as the authors thought they were to use podcasts for repetitive or supplemental learning purposes.

A number of factors could possibly account for these findings. One of the reasons may be that vocabularies in form of audio podcasts plus still as well as animated pictures were useful because podcasts provided timesaving and easy-to-use technology for learners. Students used their talents and abilities, their learning motivation and attitude improved and they promoted their vocabulary knowledge. The other reason could be that the content and the clear native pronunciation of the podcasts attracted learners' attentions.

\section{CONCLUSION}

The research questions attempted to see whether attitude significantly affected Iranian EFL learners' vocabulary gain as well as retention applying audio podcasts plus still pictures and audio podcasts plus animated pictures in an E-learning context. The results revealed that attitude level significantly affected Iranian EFL learners' vocabulary gain and retention. The participants who had higher levels of attitude had higher levels of vocabulary gain as well as retention applying audio podcasts plus still pictures and audio podcasts plus animated pictures.

The findings of the present study are not enough. Further research is needed. The concentration of the present study was on intermediate EFL learners. The same study can be done with participants at other proficiency levels. Moreover, age and gender were not considered in this study. Therefore, interested researchers can consider these variables.

Learners must engage actively and take responsibility for their own learning in order to make a satisfying as well as productive learning experience. The demand for distance learning will continue to grow and technology will continue to help distance learners to utilize new tools in order to make learning environments that prepare them for solving problems by online collaboration. 


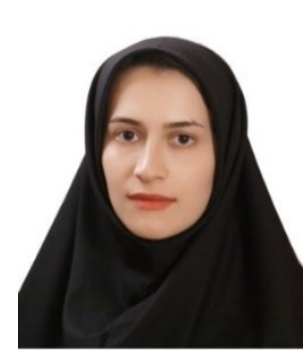

Atefeh ELEKAEI is a Ph.D. candidate in Teaching English as a Foreign Language at Islamic Azad University, Isfahan (Khorasgan) Branch, Isfahan, Iran. She received her M.A. in TEFL from Islamic Azad University of Takestan, Iran in 2012. She has more than 10 years of experience in teaching English at institutes, graduate and undergraduate programs. She has been the reviewer of different journals and has a number of publications and conference papers at international and national journals. Her major interests are Foreign/Second Language Teaching and Learning, Language Testing, Computer Assisted Language Teaching and Learning, Mobile Assisted Language Teaching and Learning, Distance Education/E-learning, Foreign/Second Language Learning Styles and Strategies, English for Academic/Specific Purposes, Motivation and Attitude.

Atefeh ELEKAEI, Ph.D. Candidate

English Department, Islamic Azad University, Isfahan (Khorasgan) Branch, Isfahan, Iran

E-mail: atefehelekaei@yahoo.com

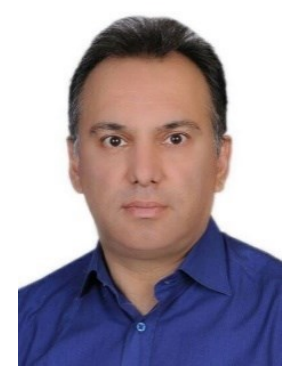

Hossein Heidari TABRIZI is an associate professor of TEFL at the English Department of Islamic Azad University, Isfahan (Khorasgan) Branch, Isfahan, Iran. He has been teaching different courses at PhD, MA, and BA levels in TEFL, Translation Studies, and General Linguistics since 1994. He has presented and published various papers at different conferences and journals both at international and national levels, and has been the reviewer of different journals or research projects. His research interests include Language Assessment and Testing, Translation Studies, Discourse Analysis, and Sociolinguistics.

Dr. Hossein HEIDARI TABRIZI, Associate Professor

English Department, Islamic Azad University, Isfahan (Khorasgan) Branch, Isfahan, Iran Phone: +98-9133141524

E-mail: heidaritabrizi@gmail.com

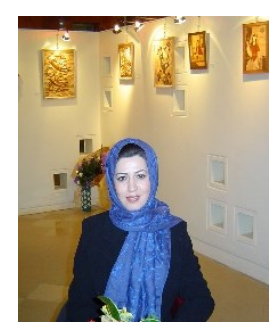

Azizeh CHALAK is an associate professor of TEFL at the English Department of Islamic Azad University, Isfahan (Khorasgan) Branch, Isfahan, Iran. She has more than 20 years of experience in teaching English at graduate and undergraduate programs in face-to-face and virtual English campuses. She is the managing editor of Research in English Language Pedagogy (RELP) published at IAU, Isfahan Branch and was selected as the top researcher of English Department in 2017 and 2018. She has presented and published many papers at different conferences and journals both at international and national levels, and has been the reviewer of different journals or research projects. Her research interests include discourse analysis, sociolinguistics, intercultural communication, e-mail communications, computer-mediated communication $(\mathrm{CMC})$, genre studies, and integration of technology in teaching.

Dr. Azizeh CHALAK, Associate Professor

English Department, Islamic Azad University, Isfahan (Khorasgan) Branch, Isfahan, Iran

Managing Editor, Research in English Language Pedagogy (RELP)

Phone: +98-9122795543

E-mail: azichalak@gmail.com 


\section{REFERENCES}

Abdous, M., Camarena, M. M., \& Facer, B. R. (2009). MALL technology: Use of academic podcasting in the foreign language classroom. ReCALL, 21(1), 76-95.

Ajzen, I. (2005). Attitudes, personality and behavior. New York: Open University Press.

Al-Seghayer, K. (2001). The effect of multimedia annotation modes on L2 vocabulary acquisition: A comparative study. Language Learning \& Technology, 5(1), 202-232.

Alshaikhi, D, \& Madini, A. A. (2016). Attitude toward enhancing extensive listening through podcasts supplementary pack. English Language Teaching, 9(7), 32-47.

Bolliger, D. U., Supanakorn, S., \& Boggs, C. (2010). Impact of podcasting on student motivation in the online learning environment. Computers \& Education, 55, 714-722.

Chan, W. M., Chi, S. W., Chin, K. N. \& Lin, C. Y. (2011). Students' Perceptions of and Attitudes towards Podcast-Based Learning - A Comparison of Two Language Podcast Projects. Electronic Journal of Foreign Language Teaching, 8(1), 312-335.

Chester, A., Buntine, A., Hammond, K., \& Atkinson, L. (2011). Podcasting in education: student attitudes, behavior and self-efficacy. Eaucational technology \& Society, 14(2), 236-247.

Darwis, R. (2016). Students' perception towards the use of podcast in learning English: A case study of the second grade students at one high school in Bandung. Journal of English and Education, 4(2), 80100 .

Ducate, L., \& Lomicka, L. (2009). Podcasting: An effective tool for Honing language students' pronunciation?. Language Learning \& Technology, 13(3), 66-86.

Elekaei, A., Faramarzi, S. \& Biria, R. (2015). Test-takers' attitude toward taking pictorial and visual modalities of listening comprehension test in an EFL context. Journal of Language Teaching and Research, 6(2), 308-315.

Evans, C. (2008). The effectiveness of m-learning in the form of podcast revision lectures in higher education. Computers and Education, 50, 491-498.

Fernandez, V., Simo, P. \& Sallan, J. M. (2009). Podcasting: A new technological tool to facilitate good practice in higher education. Computers \& Education, 53, 385-392.

Hai-peng, H., \& Li-jing, D. (2007). Vocabulary acquisition in multimedia environment. US-China Foreign Language, 5(8), 55-59.

Hasan, M. \& Hoon, T. B. (2012). ESL learners' perception and attitudes towards the use of podcast in developing listening skills. The English Teacher, 41(2), 160-173.

Istanto, J. W. (2011). Pelangi Bahasa Indonesia podcast: what, why and how? Electronic Journal of Foreign Language Teaching, 8(1), 371-384.

Lee, M. J. W., \& Chan, A. (2007). Reducing the effects of isolation and promoting inclusivity for distance learners through podcasting. Turkish Online Journal of Distance Education, 8(1), 85-104.

Li, H. C. (2010). Using podcasts for learning English: perceptions of Hong Kong Secondary 6 ESL students. Début: the undergraduate journal of languages, linguistics and area studies, 1(2), 78-90.

Lonn, S. \& Teasley, S. D. (2009). Podcasting in higher education: What are the implications for teaching and learning?. Internet and Higher Education, 12, 88-92.

Lord, G. (2008). Podcasting Communities and Second Language Pronunciation. Foreign Language Annals, 41(2), 374-389. 
Lu, M. (2008). Effectiveness of vocabulary learning via mobile phones. Journal of Computer Assisted Learning, 24, 515-525.

Masgoret, A. M. \& Gardner, R. C. (2003). Attitudes, motivation, and second language learning: A metaanalysis of studies conducted by Gardner and associates. Language Learning, 53(1), 123-163.

Mayer, R. \& Moreno, R. (2002). Aids to computer-based multimedia learning. Learning and Instruction, 12, 107-119.

Moore, M. G. (1993). Theory of transactional distance. In D. Keegan (Ed.), Theoretical principles of distance education (pp. 22-38). London, New York: Routledge.

Naseri, S., \& Motallebzadeh, K. (2016). Podcasts: A factor to improve Iranian EFL learner' self-regulation ability and use of technology. Educational Technology \& Society, 19(2), 328-339.

O’Bryan, A., \& Hegelheimer, V. (2007). Integrating CALL into the classroom: The role of podcasting in an ESL listening strategies course. ReCALL, 19(2), 162-180.

Picciano, A. G. (2002). Beyond student perceptions: Issues of interaction, presence, and performance in an online course. Journal of Asynchronous Learning Networks, 6(1), 21-40.

Plass, J. L., Chun, D. M., Mayer, R. E., \& Leutner, D. (1998). Supporting visual and verbal learning preferences in a Second-Language multimedia learning environment. Journal of Educational Psychology, 90(1), 25-36.

Putman, S. M., \& Kingsley, T. (2012). The atoms family: Using podcasts to enhance the development of science vocabulary. The Reading Teacher, 63(2), 100-108.

Rimrott, A. (2010). Computer-assisted vocabulary learning: Multimedia annotations, word concreteness, and individualized instruction. Unpublished doctoral dissertation, Simon Fraser University.

Sanjana, L. (2014). Impact of podcast on listening skills of the students of higher secondary level. Doctoral Dissertation, BRAC University.

Schmitt, N. \& Meara, P. (1997). Researching vocabulary through a word knowledge framework: word associations and verbal suffixes. Studies in second Language Acquisition, 19, 17-36.

Shahid, S. H., \& Ali, Z. (2017). Effects of video-podcasts on listening comprehension of Saudi EFL learners. European Journal of English Language Teaching, 2(4), 169-194.

Shahid, S. H., \& Ali, Z. (2017). Saudi EFL learners' attitude towards integration of video-podcasts in listening comprehension. European Journal of English Language Teaching, 2(2), 130-157.

Shoar, N. S., Abidin, M. J. Z., \& Pour-Mohammadi, M. (2011). Using podcasting as a revision tool by Iranian EFL learners. International Journal of Education, 3(2), 1-14.

Ubon, N. A., \& Kimble, C. (2004). Exploring social presence in asynchronous text-based online learning communities (OLCS). Proceedings of the $5^{\text {th }}$ International Conference on Information Communication Technologies in Education, Samos, Greece.

Walls, S. M., Kucsera, J. V., Walker, J. D., Acee, T. W., McVaugh, N. K., \& Robinson, D. H. (2010). Podcasting in education: Are students as ready and eager as we think they are?. Computers \& Education, 54, 371-378.

Zarei, A. A., \& Elekaei, A. (2012). Learner autonomy and language learning strategies: An empirical analysis. Germany: Lambert Academic Publishing. 